\title{
Highly selective transformation of poly[(R)-3-hydroxybutyric acid] into trans-crotonic acid by catalytic thermal degradation.
}

\begin{abstract}
Highly selective transformation of poly[(R)-3-hydroxybutyric acid] (PHB) into trans-crotonic acid was achieved by thermal degradation using $\mathrm{Mg}$ compounds: $\mathrm{MgO}$ and $\mathrm{Mg}(\mathrm{OH}) 2$ as catalysts. Through catalytic action, not only the temperature and Ea value of degradation were lowered by $40-50{ }^{\circ} \mathrm{C}$ and $11-14 \mathrm{~kJ}$ mol-1, respectively, but also significant changes in the selectivity of pyrolyzates were observed. Notably, $\mathrm{Mg}(\mathrm{OH}) 2$ showed nearly complete selectivity $(\sim 100 \%)$ to trans-crotonic acid. Kinetic analysis of TG profiles revealed that the catalytic thermal degradation of PHB was initiated by some random degradation reactions, followed by the unzipping $\beta$-elimination from crotonate chain-ends as a main process. It was suggested that the $\mathrm{Mg}$ catalysts promote the totality of the $\beta$-elimination reactions by acting throughout the beginning and main processes, resulting in a lowering in the degradation temperature and the completely selective transformation of PHB.
\end{abstract}

Keyword: Polyhydroxy butyrate; Catalytic depolymerization; Crotonic acid; Unzipping belimination; Kinetic analysis. 